\title{
Geometric morphometric analysis of cranial variation in the Egernia depressa (Reptilia: Squamata: Scincidae) species complex
}

\author{
Marci G. Hollenshead \\ Department of Biological Sciences, Northern Arizona University, Flagstaff, Arizona 86011, U.S.A. \\ Email: mhollenshead@citruscollege.edu
}

\begin{abstract}
Few studies have attempted to simultaneously examine geographic, ontogenetic and sexual variation of lizard crania. This study does so with a focus on the Egernia depressa species complex (Pygmy Spiny-tailed Skinks), which occur throughout much of arid Western Australia and inhabits fallen trees in the southern part of its range and rock crevices in disjunct boulder outcrops in the northern part of its range in the Pilbara. Geometric (i.e. landmark-based) morphometrics were used to examine variation in cranial shape in E. depressa, E. cygnitos and E. epsisolus. Cranial differences were evident among the different species; however, the differences depended on which aspect of the cranium was being analysed. A comparison also was made between $E$. depressa which inhabits tree hollows v. E. cygnitos and E. epsisolus which use rock crevices. The lateral aspect of the cranium of the rock-inhabiting species differs from the log-inhabiting species in having dorsal-ventral compression of the postorbital region. Egernia cygnitos which lives western portion of the Pilbara differs from other species in having a wider cranium with a correspondingly broader palatal region. Sexual dimorphism was not evident, but ontogenetic changes in cranial form were present.
\end{abstract}

KEYWORDS: Australian skinks, Pygmy Spiny-tailed Skinks, Western Australia, landmark-based methods.

\section{INTRODUCTION}

The Australian scincid genus Egernia includes some of the continent's largest and most ubiquitous lizards (Greer 1989; Cogger 2000). The genus previously included 30 species divided into six species-groups based on external morphology (Storr 1968, 1978; Horton 1972). These groupings were later thought to be based on convergent characters, and therefore did not necessarily reflect phylogenetic relationships (Chapple 2003). Recently, a molecular phylogenetic study (Gardner et al. 2008) supported the latter view, and Egernia was divided into four genera (Egernia, Liopholis, Bellatorias, Lissolepis).

Several species of Egernia (sensu Cogger 2000) are among the most social of squamate reptiles and exhibit a high degree of mate fidelity (see Chapple 2003 for a review of Egernia natural history and social behaviour). Several studies have shown that these lizards live in long-term stable social groups that consist of closely related individuals (see Bull et al. 2001; Gardner et al. 2001, 2002; Duffield and Bull 2002; and others). Egernia generally exhibit a strong attachment to a refuge, such as a rock crevice, hollow log or burrow. These refuges provide shelter and most of the lizards' activities occur near their retreat site. Many species will repeatedly defecate at the same location, creating scat piles near their crevice (Greer 1989). Within their stable social groups, several individuals will occupy the same crevice, bask in close proximity and share the same scat pile (Duffield and Bull 2002). Anecdotal reports (Horner 1992) and personal observations of several individuals within the E. depressa species complex occupying the same crevice suggest they also may live in stable social groups.

Little is known of the natural history of members of the E. depressa species complex besides their distribution and defensive behavior (Hutchinson 1993). This species complex occurs in the western half of Western Australia (WA) with isolated populations in the interior of WA (Storr 1978) and in the southwestern corner of the Northern Territory (NT; Horner 1992). In the Pilbara, a rocky region in the northern part of WA (Figure 1), E. cygnitos and E. epsisolus are reddish (pink) and brown with dark spots posteriorly that form transverse bands. It is in this area of their distribution that they shelter in rock crevices. However, in the southern part of their distribution (Figure 1), E. depressa finds shelter in hollows of trees, particularly Acacia (mulgas) and are brown anteriorly and gray with dark spots posteriorly that tend to form transverse bands (Storr 1978; Cogger 2000; Wilson and Swan 2003). Egernia eos is a geographically isolated species within this complex that lives in central Australia; this species was not examined in this study. 
TABLE 1 List of specimens used in analysis. Snout-vent length (SVL) > $100 \mathrm{~mm}$ considered an adult. SVL, snoutvent length; TL, total length. Egernia depressa (Ed), Egernia cygnitos (Ec) and Egernia epsisolus (Ee).

\begin{tabular}{|c|c|c|c|c|c|c|}
\hline $\begin{array}{l}\text { WAM } \\
\text { Specimen \# }\end{array}$ & SVL (mm) & $\mathrm{TL}(\mathrm{mm})$ & Mass (g) & Sex & Species & GPS \\
\hline R162909 & 112 & 140 & 42.0 & $\mathrm{~F}$ & Ed & S24 17' 37.3": E114 02' 38.4": 25 M ALT. + 6 M \\
\hline R162910 & 78 & 112 & 13.5 & $\mathrm{~F}$ & Ed & S24 17' 30.3": E114 02’ 18.3”: 25 M ALT. + 6 M \\
\hline R162911 & 94 & 128 & 35.0 & M & $\mathrm{Ed}$ & S24 17' 37.6": E114 02' 38.7”: 25 M ALT. + 6 M \\
\hline R167571 & 77 & 105 & 14.0 & $\mathrm{~F}$ & Ed & S24 17' 43.5"; E114 02' 39.5"; 25 M ALT. + 4 M \\
\hline R167572 & 72 & 97 & 10.5 & $\mathrm{~F}$ & Ed & S24 17' 49.4"; E114 02' 39.2"; 25 M ALT. + 4 M \\
\hline R167573 & 102 & 141 & 38.0 & $\mathrm{M}$ & Ed & S24 17' 49.4"; E114 02' 39.2"; 25 M ALT. + 4 M \\
\hline R167577 & 110 & 145 & 46.0 & $\mathrm{~F}$ & Ed & S24 17' 49.6"; E114 02' 40.8"' 25 M ALT. + 5 M \\
\hline R167600 & 103 & 145 & 34.0 & M & $\mathrm{Ec}$ & S22 46' 54.3"; E115 05' 02.2"; 91 M ALT. + 4 M \\
\hline R167602 & 103 & 145 & 34.0 & $\mathrm{~F}$ & Ec & S22 46' 54.8"; E115 05' 03.0"; 91 M ALT. + 4 M \\
\hline R167606 & 97 & 134 & 25.0 & $\mathrm{~F}$ & $\mathrm{Ec}$ & S22 46' 54.6"; E115 05'03.0"; 91 M ALT. + 4 M \\
\hline R167608 & 106 & 145 & 33.0 & $\mathrm{~F}$ & Ec & S22 46' 54.6"; E115 05' 03.0"; 91 M ALT. + 4 M \\
\hline R167609 & 79 & 110 & 13.0 & $\mathrm{~F}$ & Ec & S22 46' 54.6"; E115 05' 03.0"; 91 M ALT. + 4 M \\
\hline $\mathrm{R} 167612$ & 96 & 132 & 23.5 & M & $\mathrm{Ec}$ & S22 46' 54.7"; E115 05' 02.6"; 94 M ALT. + 6 M \\
\hline $\mathrm{R} 167613$ & 108 & 151 & 35.5 & $\mathrm{~F}$ & $\mathrm{Ec}$ & S22 46' 54.7"; E115 05' 02.6"; 94 M ALT. + 6 M \\
\hline $\mathrm{R} 167616$ & 106 & 142 & 37.5 & M & Ec & S22 46' 54.7"; E115 05' 02.6"; 94 M ALT. + 6 M \\
\hline R167617 & 83 & 116 & 17.0 & $\mathrm{~F}$ & Ec & S22 46' 54.7"; E115 05' 02.6"; 94 M ALT. + 6 M \\
\hline $\mathrm{R} 167618$ & 86 & 117 & 17.0 & M & Ec & S22 46' 54.7"; E115 05' 02.6"; 94 M ALT. + 6 M \\
\hline R167650 & 83 & 115 & 12.0 & $\mathrm{~F}$ & $\mathrm{Ee}$ & S20 56' 48.3"; E117 39' 17.3"; 57 M ALT. + 4 M \\
\hline $\mathrm{R} 167653$ & 112 & 157 & 39.0 & $\mathrm{~F}$ & $\mathrm{Ee}$ & S21 06' 52.3"; E118 42' 08.1"; 156 M ALT. + 5 M \\
\hline $\mathrm{R} 167656$ & 104 & 143 & 32.5 & M & $\mathrm{Ee}$ & S21 06' 53.6"; E118 42' 06.4"; 156 M ALT. + 4 M \\
\hline R167658 & 105 & 145 & 32.5 & M & $\mathrm{Ee}$ & S21 06' 53.6"; E118 42' 06.9"; 156 M ALT. + 4 M \\
\hline $\mathrm{R} 167660$ & 105 & 143 & 31.5 & M & $\mathrm{Ee}$ & S21 14' 52.9"; E118 41' 45.9”; 179 M ALT. \\
\hline R167662 & 102 & 139 & 33.0 & M & $\mathrm{Ee}$ & S21 14' 54.1"; E118 41' 49.0"; 179 M ALT. + 4 M \\
\hline $\mathrm{R} 167663$ & 111 & 151 & 41.0 & M & $\mathrm{Ee}$ & S21 14' 54.1"; E118 41' 49.0"; 179 M ALT. + 4 M \\
\hline $\mathrm{R} 167664$ & 94 & 121 & 22.5 & M & $\mathrm{Ee}$ & S21 14' 54.1"; E118 41' 49.0"; 179 M ALT. + 4 M \\
\hline R165230 & 101 & NA & NA & $\mathrm{M}$ & $\mathrm{Ee}$ & $\mathrm{S} 21 ; \mathrm{E} 117$ \\
\hline R162907 & 116 & 150 & 37.0 & $\mathrm{~F}$ & $\mathrm{Ee}$ & S20 50’41.8”; E117 47’46.8”; 41 M ALT. + 6 M \\
\hline R162908 & 83 & 120 & 18.3 & M & $\mathrm{Ee}$ & S20 50’41.8”; E117 47’46.8”; 41 M ALT. + 6 M \\
\hline
\end{tabular}




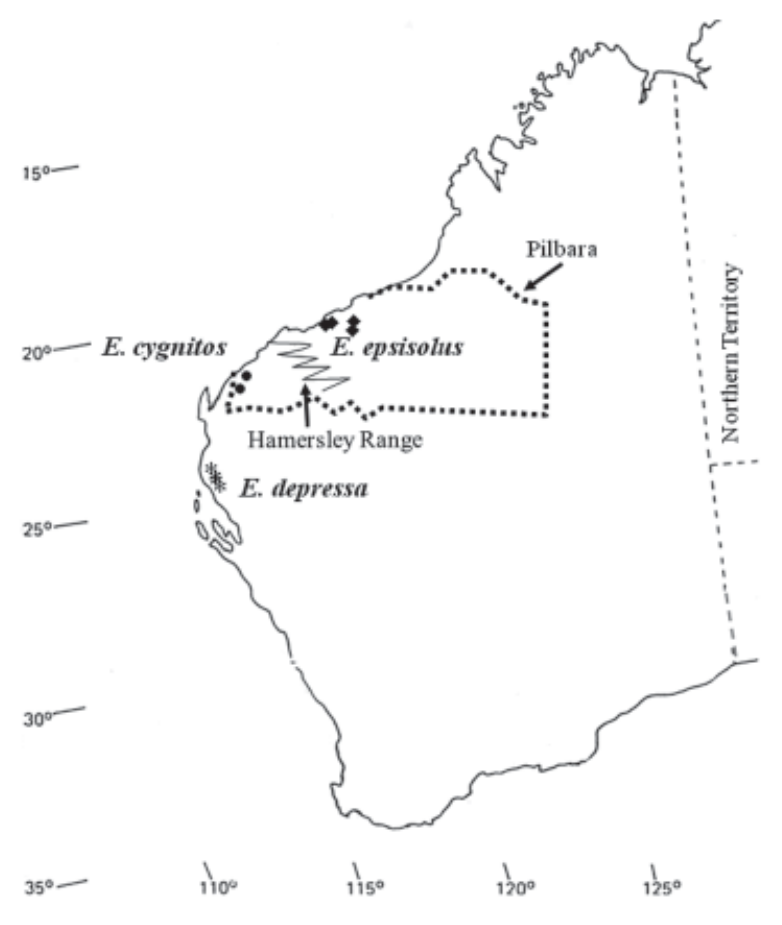

FIGURE 1 Collecting sites of E. depressa species complex: * log-dwelling species from the southern portion of its distribution (E. depressa), - represents the western rock-dwelling species from the Pilbara (E. cygnitos), and represents the eastern rock-dwelling species from the Pilbara (E. epsisolus).

Egernia depressa, E. cygnitos and E. epsisolus crania were examined to document geographic, ontogenetic and sexual variation within this species complex. Specifically, I tested two hypotheses. First, I hypothesized that cranial shape exhibits greater variation among than within the three recently (re) described species (Doughty et al. 2011), formerly considered populations of one species. Second, I hypothesized that cranial shape differs among species utilizing different refuge types (log hollows v. rock crevices), which may reflect behavioral differences in refugia use. These hypotheses are not mutually exclusive and were tested in combination. To test these hypotheses, cranial shape variation was quantified using geometric (i.e. landmark-based) morphometrics. To rigorously conduct this comparison, it was necessary to first identify any morphological variation resulting from ontogeny and/or sexual differentiation.

\section{MATERIALS AND METHODS}

\section{SPECIMENS}

The sample consisted of 28 dry skulls (Table 1). We collected 27 individuals within the E. depressa species complex during the Australian winters of 2005 and 2006; an additional specimen, WAM R165230, was also analyzed. After hand capture, lizards were euthanased by injecting pentobarbital into the heart. Total length (TL), snout-vent length (SVL) and mass were measured and sex was determined for each individual. Stomachs with their contents were removed, and liver samples were taken, for future analyses of diet and genetic variation, respectively. For each locality, GPS coordinates were recorded. The entire specimen was skeletonized using a dermestid beetle colony. Bleach was used to remove osteoderms so that individual skull elements and the sutures among them could be examined.

A thorough analysis of intraspecific and interspecific variation requires representation of individual, sexual and ontogenetic variation within the sample. I tried to obtain a representative sample by collecting both sexes, juveniles and adults of each species. Storr (1978) gives a range for juvenile to adult SVL as 54-117 $\mathrm{mm}$. Cogger (2000) provides an average adult SVL of the E. depressa species complex as $100 \mathrm{~mm}$. The size at maturity is unknown for this species complex. For this analysis, specimens with a SVL of $\geq 100 \mathrm{~mm}$ were considered adults using Cogger's (2000) estimate of average adult SVL. However, I recognize that the size of maturity is most likely smaller than $100 \mathrm{~mm}$.

Collected specimens ranged from 72 to $116 \mathrm{~mm}$ SVL. Four of the lizards from $E$. depressa, the log-dwelling species, $\left(24^{\circ} 17^{\prime} 30.3-49.6^{\prime \prime} \mathrm{S}, 114^{\circ} 02^{\prime} 18.3-40.8^{\prime \prime} \mathrm{E}\right)$ were juveniles (1 male, 3 females), and three were adults (1 male, 2 females). From E. cygnitos, the rock-dwelling western Pilbara species $\left(22^{\circ} 466^{\prime} 54.3-54.7^{\prime \prime} \mathrm{S}, 115^{\circ} 05^{\prime} 0.2-\right.$ 0.3 'E), five were juveniles ( 2 males, 3 females), and five were adults ( 2 males, 3 females). Three E. epsisolus, the rock-dwelling eastern Pilbara (E. epsisolus) species $\left(20-21^{\circ} 06\right.$ 'S, $\left.117-118^{\circ} 42^{\prime} \mathrm{E}\right)$, were juveniles (2 males, 1 female), and eight were adults (6 males, 2 females). See Table 1 for a detailed specimen list with Western Australia Museum (WAM) catalog numbers, TL, SVL, mass, sex, population and GPS coordinates.

\section{GEOMETRIC MORPHOMETRICS}

Geometric morphometrics is a landmark-based method that facilitates a true analysis of shape variation because, unlike linear morphometric data, relationships among landmarks allow resolution of shape differences (Lockwood et al. 2002). For each species, the dorsal, ventral and lateral aspect of the cranium was characterized using two-dimensional landmarks. First, a high-resolution digital image of each aspect of the cranium was captured using a Nikon Coolpix 995 digital camera. To reduce parallax error, I standardized the image capture procedure. The cranium and camera lens had the same orientation for each image. Clay and blocks were used to hold the cranium in the same orientation for the dorsal, ventral and lateral aspects. The camera was on a tripod and a level was used to ensure the same camera orientation. Landmarks were digitized on the images using tpsDig2.05 (Rolf 2006). I followed the landmark criteria in that the landmarks (1) are homologous anatomical loci, (2) do not change their topological positions relative to other landmarks, 


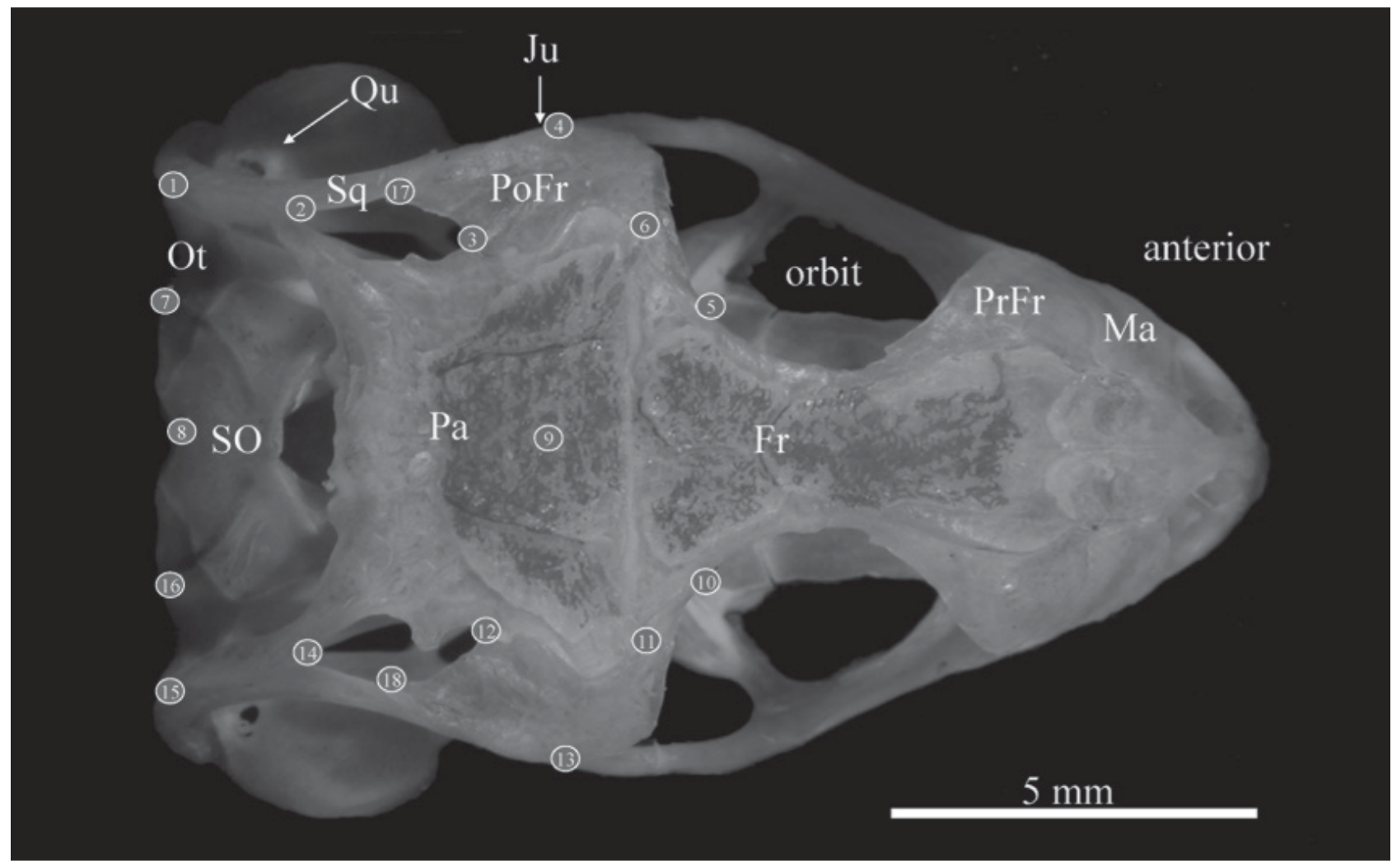

FIGURE 2 Dorsal view of cranium showing landmarks used in this study (WAM R167608). Fr, frontal; Ju, jugal; Ma, maxilla; Ot, otoccipital; Pa, parietal; PoFr, postfrontal; PrFr, prefrontal; Qu, quadrate; SO, supraoccipital; Sq, squamosal. Scale bar $=5 \mathrm{~mm}$.

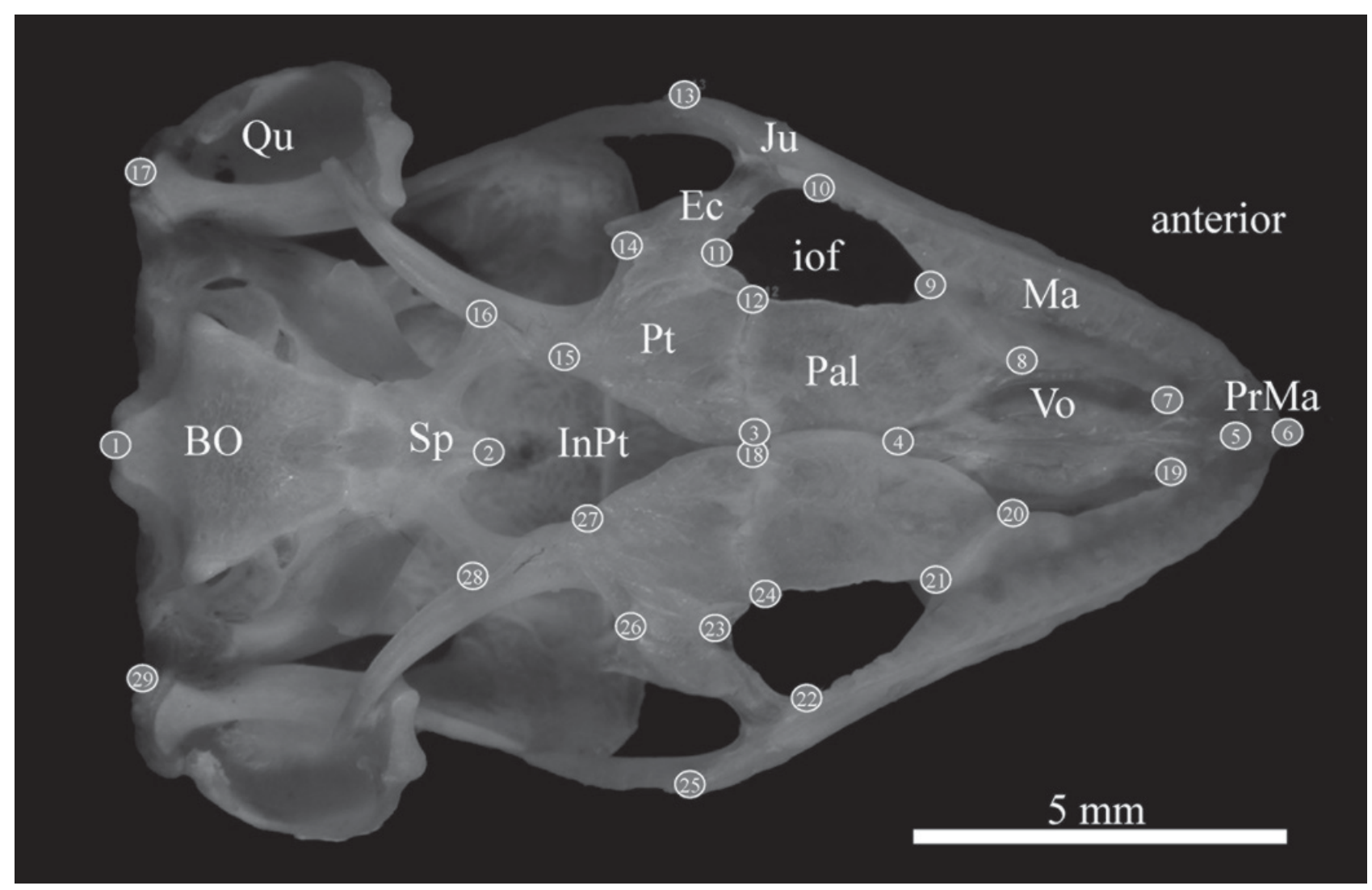

FIGURE 3 Ventral view of cranium showing landmarks used in this study (WAM R167618). BO, basioccipital; Ec, ectopterygoid; InPt, interpterygoid vacuity; iof, infraorbital fenestra; Ju, jugal; $\mathrm{Ma}$, maxilla; $\mathrm{Pa}$, palatine; PrMa, premaxilla; Pt, pterygoid; Qu, quadrate; Sp, sphenoid; Vo, vomer. Scale bar $=5 \mathrm{~mm}$. 


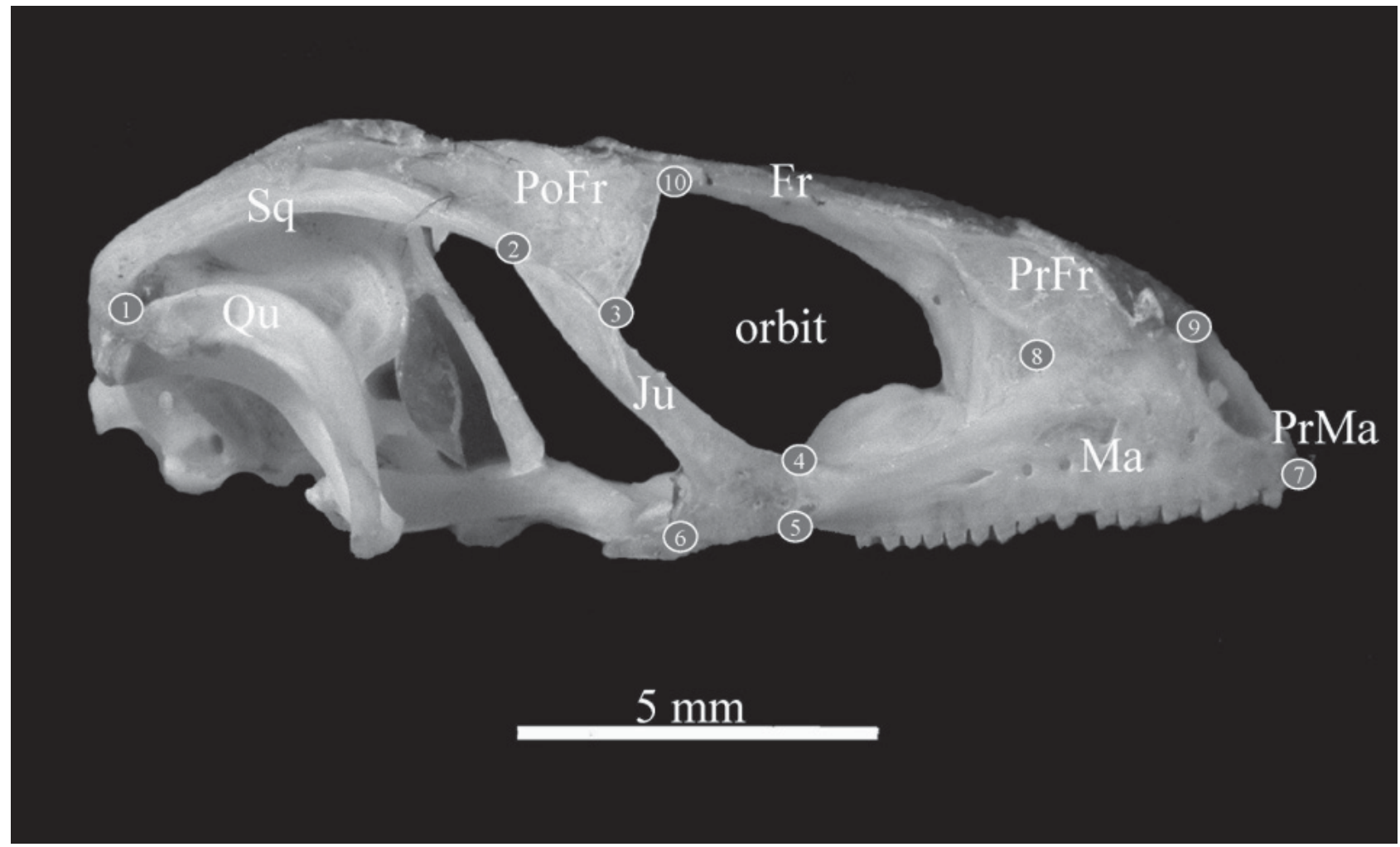

FIGURE 4 Lateral view of cranium showing landmarks used in this study (WAM R167571). Fr, frontal; Ju, jugal; Ma, maxilla; PoFr, postfrontal; PrFr, prefrontal; PrMa, premaxilla; Qu, quadrate; Sq, squamosal. Scale bar = $5 \mathrm{~mm}$.

(3) offer sufficient coverage of the morphology, (4) can be located consistently and (5) lie within the same plane (Bookstein 1991; Zelditch et al. 2004). On the dorsal aspect of the cranium, 18 landmarks were digitized on the post-orbital region (Figure 2). No landmarks were placed on the anterior portion of the cranium because that region was either damaged by the removal of osteoderms or obstinate osteoderms impeded the precise placement of landmarks. On the ventral aspect of the cranium, 29 landmarks were digitized (Figure 3). The dorsal and ventral aspects of the cranium were each assumed to be structurally bilaterally symmetrical; therefore, I used the program BigFix6 (Sheets 2003) to average the landmarks across the midline. All statistical analyses were conducted on these half configurations; this includes ten landmarks on the dorsal aspect and 17 landmarks of the ventral aspect of the cranium. Landmarks 8 and 9 and landmarks 1, 2, 4, 5 and 6 were used as the axis of symmetry for the dorsal and ventral view, respectively. On the lateral aspect of the cranium, 10 landmarks were digitized (Figure 4). Tables 2, 3 and 4 list the anatomical positions of the digitized landmarks for the dorsal, ventral and lateral aspect of the cranium, respectively.

Integrated Morphometrics Program (IMP) software package (Sheets 2003) was used for the shape analysis. I used the generalized least squares Procrustes superimposition (GLS) method to minimize distances among configurations. The Procrustes coordinates were then used for a canonical variates analysis (CVA), which explored differences between groups. Each pair-wise comparison was analysed using the program TwoGroup6h, which performs Goodall's F and resampling tests. Goodall's F tests if the difference between samples using partial Procrustes distances is significant. This test makes the assumption that the data are normally distributed; therefore, resampling tests were used to determine whether cranium shape differs among groups. One iteration involved drawing two bootstrap sets with replacement from the pooled group of specimens and the F-ratio was computed from the two sets. After 4,900 (the most provided by the program) iterations were completed, the bootstrap sets with a F-value at least as large as the original set were counted. This number was divided by the number of iterations and provides the probability of attaining the original sample (Zelditch et al. 2004).

Deformation grids illustrate the shape differences between groups using the mean configuration of that group, and the vectors show relative landmark displacement (Zelditch et al. 2004). For illustration purposes, landmark displacements were interpreted from GLS on symmetrized (BigFix6) and back-reflected configurations (lmedit6). Statistical analyses were performed on symmetrized data to minimize degrees of freedom (Zelditch et al. 2004).

To compare the ontogenies of shape between the species, I used a multivariate regression with shape 
TABLE 2 Definitions of landmarks used on the dorsal aspect of the skull. Landmarks 1-7, 17 are from the left side, 10-16, 18 are from the right side, and 8 and 9 are from the midline of the skull.

\section{Number Definition of landmark}

$1 \& 15 \quad$ Posterior-most contact between parietal and squamosal

$2 \& 14 \quad$ Anterior-most contact between parietal and squamosal

$3 \& 12 \quad$ Posterior-most contact between parietal and postfrontal

$4 \& 13$ Squamosal-jugal-postfrontal contact

$5 \& 10 \quad$ Anterior-most contact of the frontal and postfrontal

$6 \& 11$ Parietal-frontal-postfrontal contact

7 \& $16 \quad$ Posterior semicircular canal along posterior edge of skull

$8 \quad$ Midpoint of supraoccipital notch dorsal to foramen magnum

$9 \quad$ Centre of foramen in parietal

$17 \& 18$ Medial contact of the squamosal and postfrontal

as the dependent variable and size as the independent variable. For each species separately, shape variables (full set of coordinates obtained by GLS) were regressed on $\log$ transformed centroid size using Regress6k (IMP software; Zelditch et al. 2003). To examine if the species differ in shape through ontogeny, I compared the angle between the species-specific regression vectors using VecCompare6 (IMP software; Zelditch et al. 2003). A within-species vector consists of all regression coefficients of the shape variables (partial warp scores) on the log-transformed centroid size. The angles between the vectors within each species are estimated using a resampling technique (bootstrapped 400 times). The within-species angles were compared to the between-species angle. If the between-species angle is larger than the $95 \%$ range of the bootstrapped withinspecies angles, the between-species angle is significantly different and the ontogenetic allometries differ (Zelditch et al. 2003).

To assess measurement error, I analysed repeats of one adult E. cygnitos (WAM R167602). Specimen WAM R167602 was photographed on five separate occasions.

TABLE 3 Definitions of landmarks used on the ventral aspect of the skull. Landmarks 3, 7-17 are from the left side, $18-29$ are from the right side, and 1-2 and 4-6 mark the midline of the skull.

\section{Number Definition of landmark}

1

2

$3 \& 18$

4

5

6

$7 \& 19$

$8 \& 20$

$9 \& 21$

$10 \& 22$

$11 \& 23$ Notch of palatal process of ectopterygoid

$12 \& 24 \quad$ Lateral contact between pterygoid and palatine

$13 \& 25 \quad$ Posterior point of jugal flange

$14 \& 26$ Posterior-most contact between ectopterygoid and pterygoid

$15 \& 27 \quad$ Anteromedial origin of quadrate process of pterygoid

$16 \& 28$ Posterior-most point of basipterygoid process

$17 \& 29 \quad$ Midpoint of basioccipital condyle 

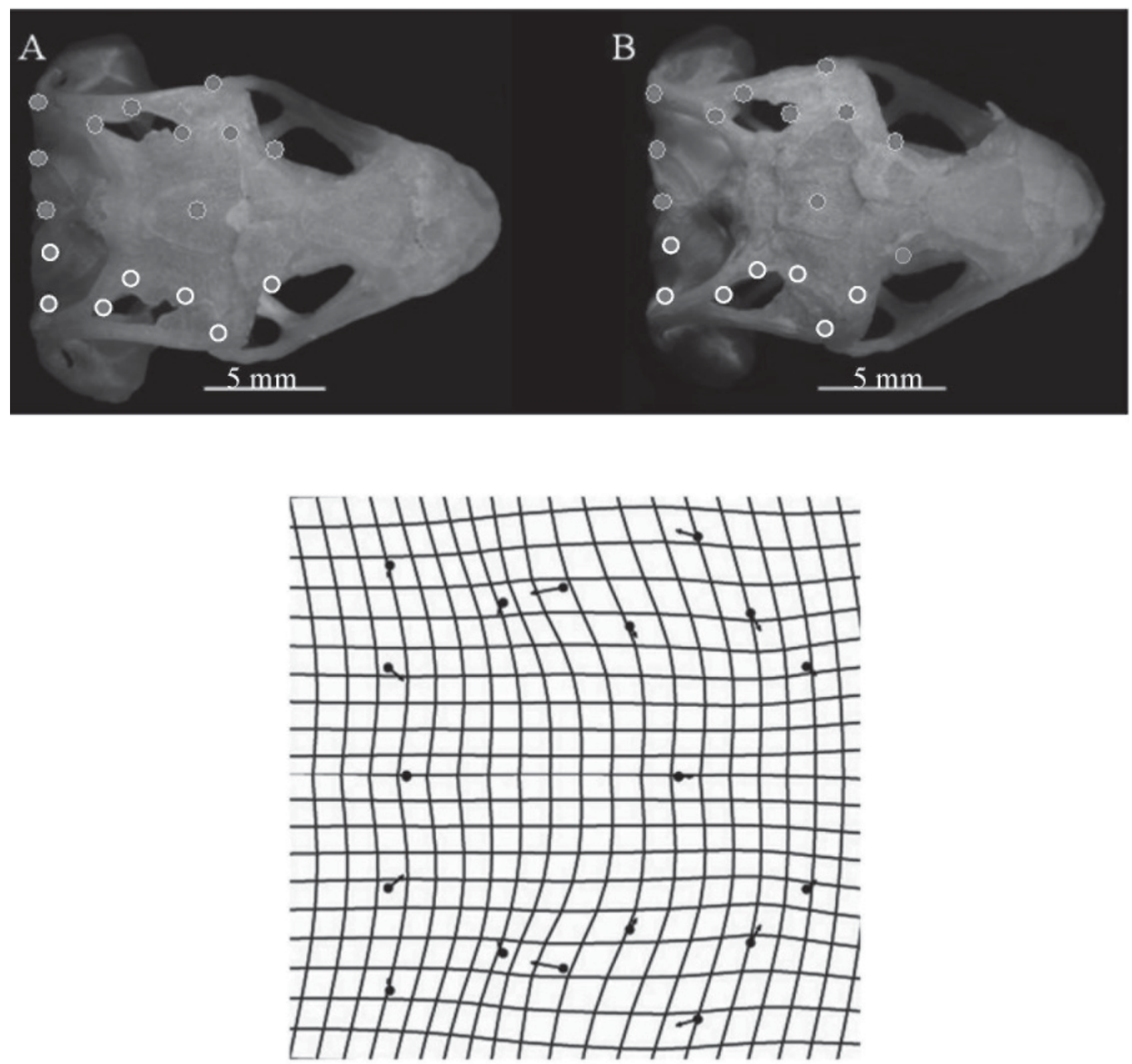

FIGURE 5 Dorsal view of cranium with landmarks. Deformation grid shows shape change from A (E. epsisolus; WAM R167663) to B (E. cygnitos; WAM R167608). Vectors display relative landmark displacement. Scale bar $=5 \mathrm{~mm}$.

All five images were landmarked at different times to provide a repeat sample of five configurations. These were compared with the configuration of a different specimen (WAM R167608) to test if the difference between WAM R167602 and WAM R167608 was greater than the variance among the repeat samples for WAM R167602. WAM R167608 was chosen because it is from the same species, the same sex and of similar size. The first principal component described $61.2 \%$ of the variation between the repeat sample (mean of repeat sample $=0.0063$ [range: 0.0032-0.0089]) and the cranium (WAM R167608 $=-0.0317$ ). The second principal component (mean of repeat sample $=0.0003$ [range: -0.0095-0.0125]; WAM R167608 = -0.0010), which explained $14.6 \%$ of the variation, described differences within the repeat sample of WAM R167602. This shows that there was less variation within the repeat sample than between different individuals which is expected if there is minimal measurement error.

\section{RESULTS}

Statistical analyses stated above were used to determine whether pooling the sexes and individuals at different ontogenetic stages was justified. The sexes from the three species were pooled because there were no significant differences between males and females within species or among the species that I sampled. I do not have any individuals with a SVL less than 72 $\mathrm{mm}$, and therefore, do not have a complete ontogenetic 
TABLE 4 Definitions of landmarks used on the lateral aspect of the skull. The right side of the skull was digitized.

\section{Number Definition of landmark}

1 Lateral-most contact between squamosal
and quadrate

2 Squamosal-jugal-postfrontal contact ventral-most point of the postfrontal where it contacts the jugal)

Maxilla-jugal contact (dorsal)

$5 \quad$ Maxilla-jugal contact (ventral)

6 Posterior-most point of jugal flange

$7 \quad$ Anterior-most point of premaxilla at tooth base

$8 \quad$ Maxilla-prefrontal contact along orbit

$9 \quad$ Dorsal-most point of nasal

10

Postfrontal-frontal contact along dorsal portion of orbit series of the E. depressa species complex. Bootstrapped $P$-values are given unless otherwise indicated.

Considering the dorsal aspect, male and female crania did not differ significantly whether adults and juveniles were analysed together $(P=0.974)$, only adults $(P=$ $0.977)$, or only juveniles $(P=0.768)$. Therefore, the entire sample of lizards was pooled for this analysis (Table 5). Dorsal cranial shape of E. cygnitos (rockdwelling western Pilbara species) differed from $E$. depressa (log-dwelling southern species; $P=0.029$ ) and E. epsisolus (rock-dwelling eastern Pilbara species; $P=$ 0.030). The cranium of individuals in E. cygnitos was wider at the jugal-squamosal contact but narrower at the squamosal-quadrate contact (Figure 5). The shape of the upper temporal fenestration and contacts between the postfrontal-squamosal differed among the species. In E. cygnitos, the postfrontal-squamosal contact was more posterior (relative to E. epsisolus) or posterolateral (relative to $E$. depressa). This was reflected by a more rounded upper temporal fenestration in individuals from E. cygnitos. When only adults were examined, a similar pattern emerged, although only $E$. cygnitos and $E$. epsisolus were statistically different $(P=0.02)$.

During ontogeny, the upper temporal fenestra lengthened from anterior to posterior. The posterior semicircular canal of the otoccipital (posterior region of braincase) constricted toward the occipital condyle. The parietal processes were wider and the lateral portion of the otoccipital was more robust. The log-dwelling

TABLE 5 Statistical results of GM analysis of the dorsal aspect of skull. Significant results are in bold.

\section{Goodall's F $\quad P$ value $\quad$ Bootstrapped (4900 times)}

\section{Sexes}

$\begin{array}{lll}\text { M vs F (all) } & 0.42 & P=0.974 \\ \text { M vs F (adults) } & 0.42 & P=0.977 \\ \text { M vs F (juv) } & 0.72 & P=0.768\end{array}$

\section{Species}

E. depressa v. E. cygnitos (all)

2.58

E. depressa v. E. epsisolus (all)

E. cygnitos v. E. epsisolus (all)

E. depressa v. E. cygnitos (adults)

E. depressa v. E. epsisolus (adults)

E. cygnitos v. E. epsisolus (adults)

E. depressa v. E. cygnitos (juv)

E. depressa v. E. epsisolus (juv)

E.cygnitos v. E. epsisolus (juv)
0.68
$P=0.001$<smiles>[Te]=[W]=[Te]</smiles>

$P=0.748$

$P<0.001$

$P=0.030$

$P=0.047$

$P=0.157$

$P=0.642$

$P<0.001$

$P=0.020$

$P=0.086$

$P=0.992$

$P=0.804$ 

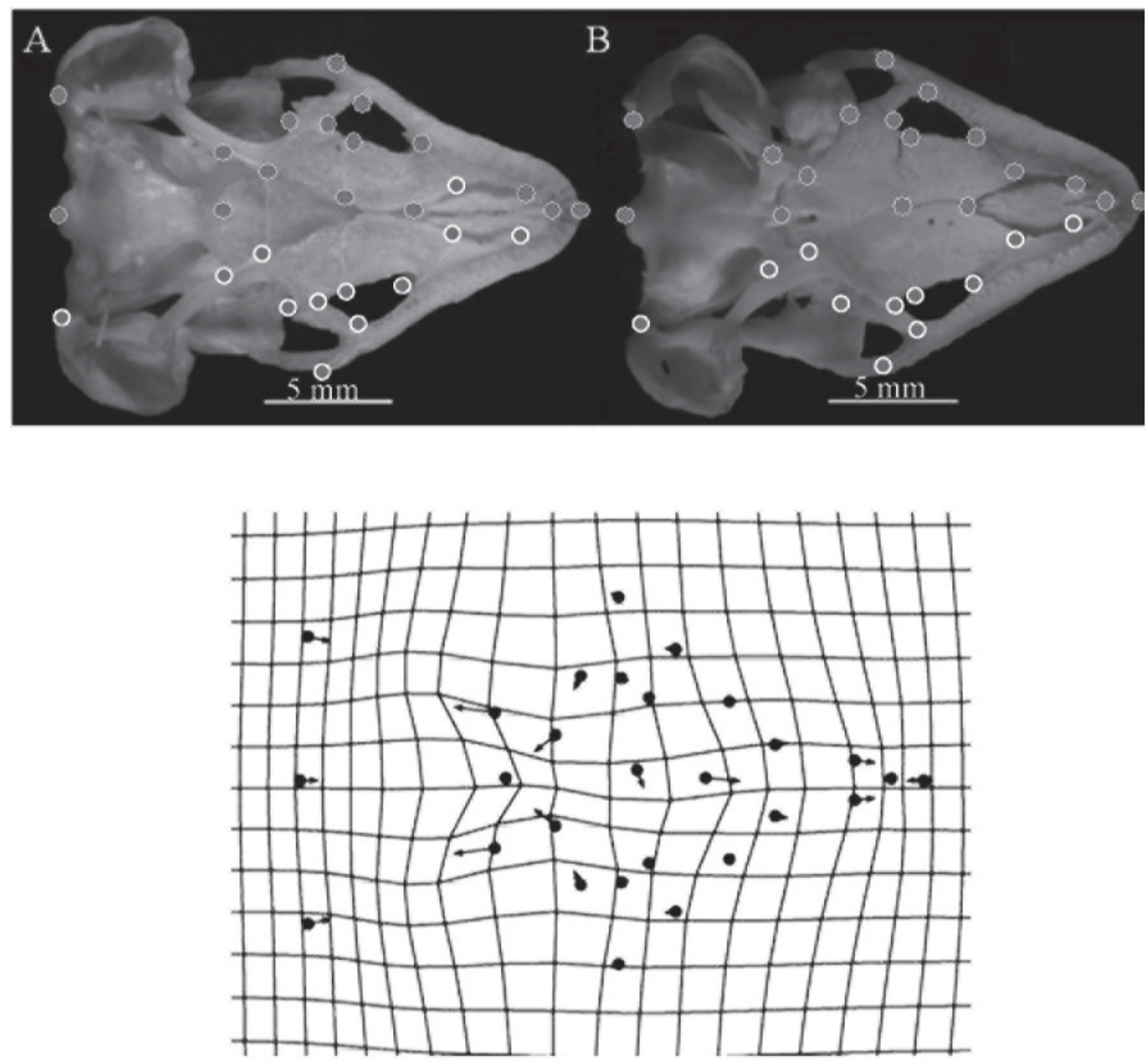

FIGURE 6 Ventral view of cranium with landmarks. Deformation grid shows shape change from A (E. epsisolus; WAM R167660) to B (E. cygnitos; WAM R167602). Vectors display relative landmark displacement. Scale bar $=5 \mathrm{~mm}$.

species (E. depressa) differed from E. cygnitos and E. epsisolus in its ontogeny; the between-species vector angle (115.7, 117.7, respectively) was greater than the within-species vector angle for E. depressa (69.3) and E. cygnitos (80.9) as well as E. depressa (71.4) and $E$. epsisolus (113.8; Table 8). Although all species showed a similar ontogeny, E. depressa appeared more extreme in the shape change in the posterior portion of the braincase as well as the upper temporal fenestration (Figure 8A).

From the ventral aspect, male and female crania did not differ significantly whether adults and juveniles were analysed together $(P=0.236)$, only adults $(P=$ $0.873)$, or only juveniles $(P=0.432)$, and therefore the sexes were pooled for this analysis (Table 6). The rockdwelling western Pilbara species (E. cygnitos) differed from $E$. epsisolus $(P=0.026)$ in that the cranium of $E$. cygnitos had a narrower braincase, a wider palatal region (with narrowed interpterygoid vacuity) and a slightly shorter nasal region (Figure 6). The cranium of $E$. depressa differed from E. epsisolus in having a narrower braincase and larger pterygoid $(P=0.012$ [not bootstrapped]; $P=0.122$ ). The main species difference was manifested in the adult crania of E. cygnitos. These crania had a narrowed braincase and the most complete secondary palate.

During ontogeny, the cranium exhibited a relative decrease in the size of the infraorbital fenestration, 
TABLE 6 Statistical results of GM analysis of the ventral aspect of skull. Significant results are in bold.

\section{Goodall's F $P$ value}

\section{Sexes}

M vs F (all)

M vs F (adults)

$\mathrm{M}$ vs F (juv)

\section{Species}

E. depressa v. E. cygnitos (all)

E. depressa v. E. epsisolus (all)

E. cygnitos v. E. epsisolus (all)

E. depressa v. E. cygnitos (adults)

E. depressa v. E. epsisolus (adults)

E. cygnitos v. E. epsisolus (adults)

E. depressa v. E. cygnitos (juv)

E. depressa v. E. epsisolus (juv)

E.cygnitos v. E. epsisolus (juv)
1.17

0.71

1.03

$$
P=0.236
$$

$P=0.873$

$P=0.432$

TABLE 7 Statistical results of GM analysis of the lateral aspect of skull. Significant results are in bold.

\section{Goodall's F $P$ value}

\section{Sexes}

M vs F (all)

M vs F (adults)

M vs F (juv)

\section{Species}

E. depressa v. E. cygnitos (all)

E. depressa v. E. epsisolus (all)

E. cygnitos v. E. epsisolus (all)

E. depressa v. E. cygnitos (adults)

E. depressa v. E. epsisolus (adults)

E. cygnitos v. E. epsisolus (adults)

E. depressa v. E. cygnitos (juv)

E. depressa v. E. epsisolus (juv)

E. cygnitos v. E. epsisolus (juv)

$\begin{array}{ll}1.42 & P=0.126 \\ 1.25 & P=0.229 \\ 1.17 & P=0.296\end{array}$

1.31

$P=0.194$

2.52

$P=0.001$

$P=0.032$

2.36

$P=0.003$

$P=0.039$

2.35

$P=0.006$

$P=0.072$

2.38

$P=0.004$

$P=0.057$

1.25

$P=0.237$

2.00

$P=0.020$

$P=0.108$

1.11

$P=0.362$

1.02 

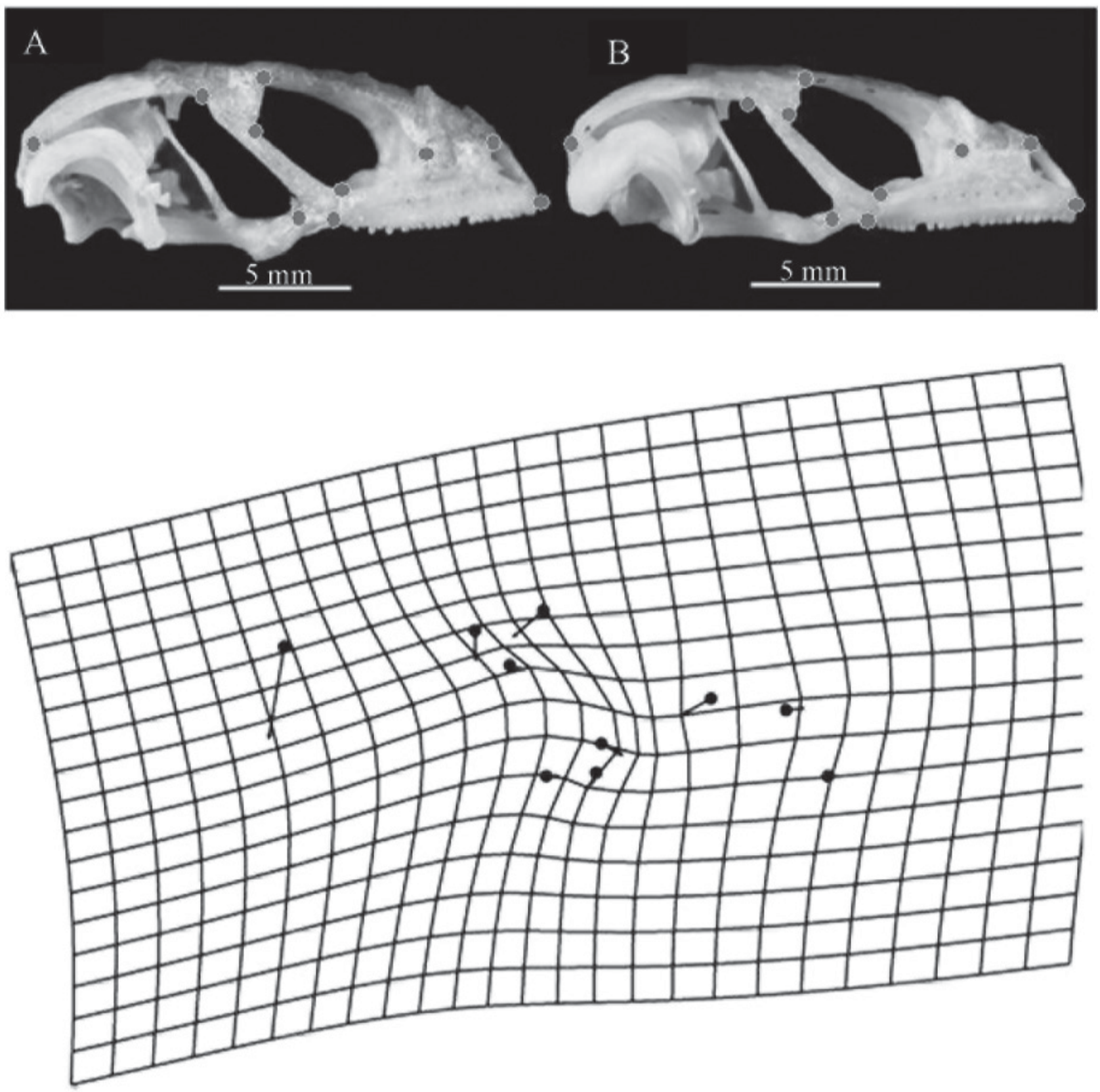

FIGURE 7 Lateral view of skull with landmarks. Deformation grid shows shape change from A (E. depressa; WAM R167577) to B (E. epsisolus; WAM R167600). Vectors display relative landmark displacement. Scale bar $=5 \mathrm{~mm}$.

and the cranium was wider at the postorbital region, specifically at the jugal flange and otoccipital-quadrate contact. Relative interpterygoid vacuity size decreased in the adult specimens (Figure 8B). The ontogeny of E. cygnitos differed from E. depressa and E. epsisolus whereas E. depressa and E. epsisolus did not differ in their ontogenetic pathway (Table 8). The betweenspecies vector angle $(66.4,96.1$ respectively) was greater than the within-species vector angle for $E$. depressa (60.8) and E. cygnitos (62.5) as well as $E$. epsisolus (55.8) and E. cygnitos (83.6), and therefore, E. cygnitos differed. The trajectories were similar in that the posterior half of the cranium was wider as the infraorbital fenestra and interpterygoid vacuity were smaller. The large palatal region reflected the difference between the trajectories of E. cygnitos and the other two species (Figure 8B; Table 8).

From the lateral aspect, male and female crania did not differ whether adults and juveniles were analysed together $(P=0.126)$, only adults $(P=0.229)$, or only juveniles $(P=0.296)$. Therefore, all specimens were pooled for this analysis (Table 7). The rock-dwelling western Pilbara species, E. cygnitos, $(P=0.006$ [not bootstrapped]; $P=0.072)$ and $E$. epsisolus $(P=0.004$ [not bootstrapped]; $\mathrm{p}=0.057$ ) differed from $E$. depressa in that E. cygnitos and E. epsisolus showed a dorsal- 
ventral compression at the postorbital region of the cranium (Figure 7). During ontogeny, the crania showed a decrease in relative orbit size and an enlargement of the post-orbital region (Figure 8C); there was not a significant difference in the ontogenetic trajectories among the species (Table 8).

\section{DISCUSSION}

The crania of the E. depressa species complex exhibited an ontogenetic shape change as well as geographic variation in shape among species. Sexual dimorphism, however, appeared to be absent in the specimens I examined. The pattern of cranial shape variation among species exhibited two patterns, depending on which aspect of the cranium is examined. The dorsal and ventral aspects of the cranium indicated that E. cygnitos (rock-dwelling western Pilbara species) differed from E. epsisolus (rock-dwelling eastern Pilbara species). Dorsally, E. cygnitos differed from E. epsisolus in having a wider cranium at the jugalsquamosal contact with lateral compression of the upper temporal fenestrations. In ventral view, E. cygnitos differed from E. epsisolus in exhibiting a compressed braincase and decreased interpterygoid vacuity (or a broader palate). The lateral aspect of the cranium showed that E. cygnitos and E. epsisolus differ from $E$. depressa (log-dwelling species). Laterally, E. cygnitos and E. epsisolus showed a dorsal-ventral compression of the cranium posterior to the orbit. These two patterns address the hypotheses of geographic isolation and habit specialization discussed below.

\section{CRANIAL SHAPE AND GEOGRAPHIC DISTRIBUTION}

I hypothesized that cranial shape differs among geographically separated species. The dorsal and ventral aspects, but not the lateral aspect, support this hypothesis since the cranial shape differs between the two rock-dwelling species (not between rock- and logdwellers). Egernia species such as E. stokesii and E. cunninghami are known not to disperse readily and live in stable social groups with closely related individuals (Gardner et al. 2001; Duffield and Bull 2002; Stow and Sunnucks 2004). In E. stokesii, the home range overlap between social groups is relatively small and dispersal in and out of species is low (Duffield and Bull 2002). Individuals within the $E$. depressa species complex may be poor dispersers as well, and my field observations suggest they too may live in stable social groups. From where I sampled, suitable habitat for E. depressa, particularly in the Pilbara, occurs as disjunct, rocky outcrops, whereas continuous suitable habitat is more readily available for the southern log-dwelling species.

Another potential barrier for the rock-dwelling species is the Hamersley Range. The Hamersley Range runs from the Fortescue River in the northeast portion of WA $460 \mathrm{~km}$ south (Figure 1). Egernia cygnitos occurs
FIGURE 8 Deformation grid illustrating ontogenetic skull shape change: A. Dorsal aspect of $E$. depressa, B. Ventral aspect of $E$. cygnitos, and C. Lateral aspect of $E$. cygnitos. Vectors display relative landmark displacement.
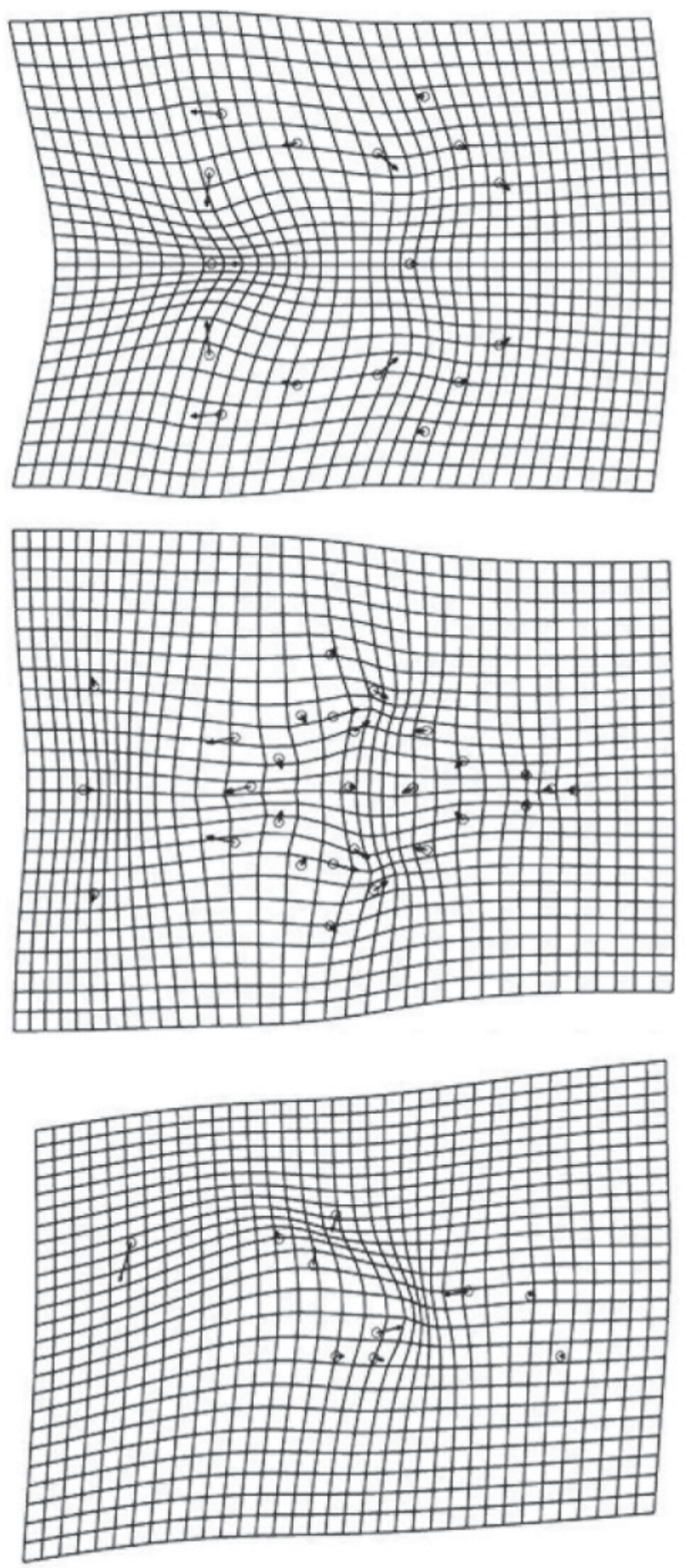

on the western side of the range while E. epsisolus is on the eastern side. These two species are separated by the highest peaks of WA, which could contribute to the differences in cranium shape (dorsal and ventral aspects) between the two rock-dwelling species. 
TABLE 8 Results of bootstrapping procedure $(\mathrm{N}=400)$ comparing regression vectors using VecCompare6.

* indicates significant results, which suggests a different ontogenetic skull shape trajectory in E. cygnitos.

\begin{tabular}{lllll} 
& $\begin{array}{l}\text { Between } \\
\text { population } \\
\text { vector }\end{array}$ & $\begin{array}{l}\text { Within } \\
\text { E. depressa } \\
\text { vector }\end{array}$ & $\begin{array}{l}\text { Within } \\
\text { E. cygnitos } \\
\text { vector }\end{array}$ & $\begin{array}{l}\text { Within } \\
\text { E. epsisolus } \\
\text { vector }\end{array}$ \\
\hline Dorsal & $115.7^{*}$ & 69.3 & 80.9 & \\
& $117.7^{*}$ & 71.4 & & 113.8 \\
& 64.2 & & 66.4 & 101.9 \\
Ventral & $66.4^{*}$ & 60.4 & 62.5 & 55.8 \\
& $96.2^{*}$ & & 83.6 & 94.1 \\
& 79.4 & 69.5 & & \\
Lateral & 60.0 & 75.9 & 67.0 & 95.7 \\
& 60.4 & 75.9 & & 82.5 \\
\hline
\end{tabular}
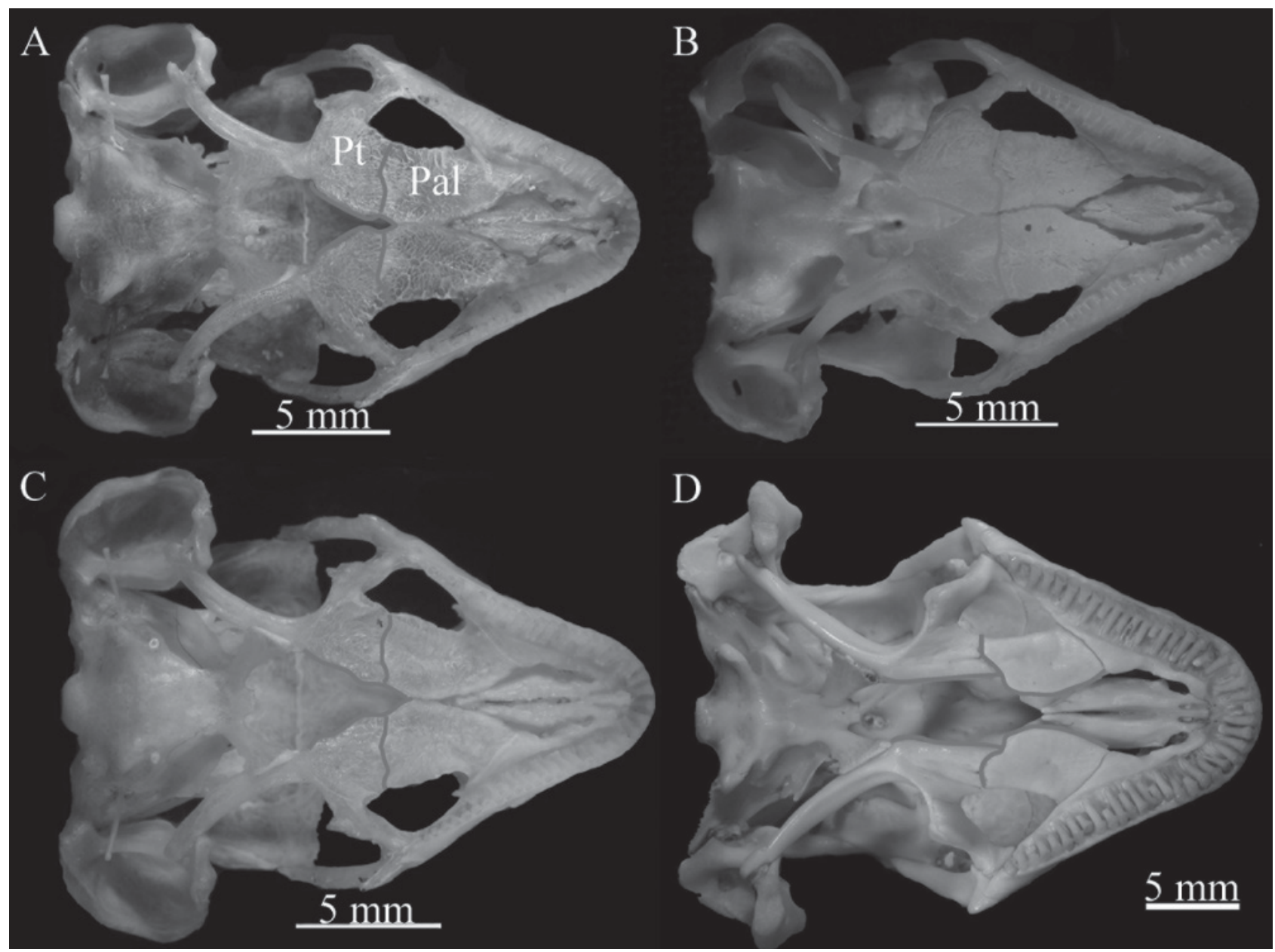

FIGURE 9 Ventral view of all three species and Egernia stokesii showing the palatal region. A. E. depressa (WAM R167577); B. E. cygnitos (WAM R167602); C. E. epsisolus (WAM R167660); D. E. stokesii (SAM 2560; photo by S.L. Swift). In E. depressa (A) and E. epsisolus (C), the palatines ( $\mathrm{Pa}$ ) meet ventrally but the pterygoids (Pt) do not. In E. cygnitos (B) the pterygoids and palatines meet at the midline of the palate. In E. stokesii (D), palatine bones, which do not meet ventrally, is the condition observed in most Egernia group species. Scale bar $=5 \mathrm{~mm}$. 


\section{CRANIAL SHAPE AND HABITAT SPECIALIZATION OR GENETIC DRIFT}

I hypothesized that the cranial shape of the rockdwelling species would differ from the log-dwelling species. The results from the lateral aspect of the cranium support this hypothesis that cranium shape variation among species of the E. depressa species complex may reflect habitat differences. Rock-dwelling lizards (E. epsisolus and E. cygnitos) show a dorsalventral compression of the postorbital region of the cranium (i.e. posterior to the orbit) when compared to the log-dwelling species, E. depressa. Egernia cygnitos and E. epsisolus differed in the dorsal and ventral aspects, but not in their lateral profiles. This is consistent with the habit both exhibit in using rock crevices as retreat sites.

When disturbed, these lizards wedge themselves into a tight crevice and inflate themselves with air, also using their spiny scales to anchor themselves (Horner 1992). Given that these lizards are strongly tied to their shelter site, the lateral aspect of the cranium exhibits variation that may functionally reflect this. Rocky habitats impose selective pressures on specific morphological traits such as flattened heads and bodies (Ingram and Covacevich 1989; Pianka and Vitt 2003; Lappin et al. 2006; Revell et al. 2007). A flattened head/body may enhance the ability to retreat deeply in to crevices because rock crevices are constrained in primarily one dimension (i.e. width of crevice as to limit the dorsal and ventral aspect of the crania). However, the refugia structure in logs tends to be more variable in three dimensions than rock crevices; therefore, a flat head may not be an ideal shape for a log-dweller (i.e. refuge dimensions in dorsal, ventral and lateral aspects of the cranium). Lab experiments are needed to test the abilities of the different species to penetrate crevices when using different substrates (rocks v. $\log s)$.

Another possible explanation for these differences may be due to random chance without any functional significance related to these cranial differences among the rock- and log-dwelling species. These are small, isolated species with potentially limited gene flow (low dispersal rates), therefore, these species level differences could be due to genetic drift without selective pressures. In addition, these differences could be due to historical morphological evolution among lineages in the past.

\section{ONTOGENY AND SEXUAL DIMORPHISM}

Ontogenetic changes in the cranium were apparent. Dorsally, shape change occurs as the upper temporal fenestra becomes larger with age. Ventrally, through ontogeny, the cranium develops a proportionately smaller infraorbital fenestration, a wider postorbital region, and the interpterygoid vacuity becomes proportionately smaller. Laterally, the crania showed a relatively smaller orbit and a larger post-orbital region through ontogeny (Figure 8). However, Hutchinson (1993) noted that in general female skinks have a greater
SVL (seen with these data) and relatively narrower heads than male skinks (not evident with these data).

No sexual dimorphism was evident in the shape of the sampled individuals within the E. depressa species complex crania. The stable social grouping and apparent lack of territoriality (Greer 1989; Chapple 2003) may be reflected by the lack of sexual dimorphism. Once again, although no direct observations of individuals within the E. depressa species complex social behavior have been published, field observations suggest that they live in social groups, which consist of more than one adult male (e.g. two adult males were found in the same shelter site in E. epsisolus). In some Egernia species, adults of both sexes will attack unrelated juveniles but not their own offspring (O'Connor and Shine 2004; While et al. 2009) and the offspring will stay with their parents for several years (Gardner et al. 2001; Stow et al. 2001; O'Connor and Shine 2003). This scenario would not occur in territorial lizard species. For example, at the other extreme, highly territorial polygynous lizards can show extreme male-biased sexual dimorphism in head size (e.g. Eumeces laticeps Vitt and Cooper 1985; Crotaphytus Lappin and Husak 2005).

\section{SECONDARY PALATE}

Skinks are unique among squamate reptiles in having a bony secondary palate with scroll-like palatine bones that enclose the choanal duct to various degrees (Greer 1970; see Rieppel et al. 2008 for overview and CT scans of squamate palates). This morphology results in a division between the breathing and food passages. Completeness of the secondary palate varies immensely among skink genera (Greer 1970). In a partial palate, the palatine bones extend only part of the way across the roof of the mouth, leaving a broad gap between the two passages. The subfamily Lygosominae (Sphenomorphus group, Egernia group and Eugongylus group), to which all Australian skinks belong, exhibit the most complete palate of all skinks (Greer 1979). In most lygosomines, the palatine bones meet or nearly meet at the midline to form a complete separation of the passages (Greer 1979; Figure 9A, $\mathrm{C}, \mathrm{D})$. The lygosomines that have this most complete palate accomplish this in one of two ways: (1) the palatines have medial processes that extend between the pterygoids, or (2) the pterygoids themselves can extend medially (Greer 1979). The former occurs in some species of the Eugongylus group (Greer 1979), whereas the latter occurs in some species of the Sphenomorphus group (Greer 1979) and Egernia cygnitos. No other species within the Egernia group (Egernia, Liopholis, Bellatorias, Lissolepis, Tiliqua, Cyclodomorphus) has a secondary palate that incorporates the pterygoids (Greer 1989; Hollenshead, unpubl. data). Most Egernia ss, Liopholis, Bellatorias and Lissolepis species have the palatines separated medially with posteriorly extended vomers. Tiliqua, Cyclodomorphus, Liopholis inornata, Liopholis striata, Egernia formosa, E. epsisolus and E. 
depressa have palatines that contact medially, whereas most individuals of Egernia cygnitos (8 of 10) have the pterygoids that are also in contact (Figure 9B; Hollenshead, unpubl. data). The functional significance of the secondary palate in skinks is not yet understood (Greer 1979).

It would be interesting to examine whether dietary tendencies are related to the cranium shape variation among E. depressa species, especially with respect to the degree of secondary palate structure. As a working hypothesis, I propose that E. cygnitos may consume harder prey. The more substantial development of its palatal region may add rigidity to the upper jaw, which would result in a more efficient transfer of forces from bilaterally contracting jaw-adductor musculature to pressure generation by the teeth on one side of the mouth. However, Pianka (1986) found 86\% Isoptera (termites) and 10\% insect larvae in 32 stomachs of logdwelling E. depressa. This high percentage of termites could indicate swarming behavior, and therefore, a readily available but highly ephemeral food source. Although these are soft-bodied arthropods, this is only a single snapshot of what these lizards eat which can change based on geographic location, season and age, with the latter worth consideration because as many Egernia species show an ontogenetic shift from omnivory to herbivory with an increase in SVL (Chapple 2003). Tiliqua species have durophagous molariform dentition and are known to eat hard prey. Their palatines contact medially yet the pterygoids do not. As stated above, this condition is seen in Tiliqua, Cyclodomorphus, E. depressa, E. epsisolus, E. formosa, Liopholis inornata and L. striata. Most Egernia sl show no medial contact of the palatines.

This study revealed variation in cranial shape in three geographically disjunct species; geographic and ontogenetic variation, but no sexual differences in cranium shape in any members of the E. depressa species complex was evident. Cranial differences were evident among the different species; however, the differences depended on which aspect of the cranium was being analysed. The lateral aspect of the cranium of the rock-inhabiting group differs from the log-inhabiting group in having dorsal-ventral compression of the postorbital region. The lizards living in the western portion of the Pilbara differ from other E. depressa in having a wider cranium with a correspondingly broader palatal region.

\section{ACKNOWLEDGEMENTS}

Thanks to J.I. Mead, C.J. Bell, A.M. Mead and S.L. Swift who helped tremendously in the field. Thanks to M.L. Zelditch and D.L. Swiderski for the informative and enjoyable geometric morphometric workshop at UC, Berkeley. I thank J.I. Meyers for helpful discussions on geometric morphometrics. I appreciate the valuable discussions with J.I. Mead (East Tennessee State University), C.J. Bell (University of Texas at Austin) and A.K. Lappin (Cal Poly Pomona) on lizard skulls. I appreciate the valuable comments on earlier versions of this manuscript provided by J.I. Mead, A.K. Lappin and two reviewers. Thanks to M. Hutchinson at South Australia Museum for use of the collection and P. Doughty, B. Maryan and C. Stevenson of WAM for all their help with the collecting, processing, and loaning of lizard specimens. All work was conducted under protocol IACUC (05-006) at Northern Arizona University. Collecting permits provided by Department of Environment and Conservation of Western Australia.

\section{REFERENCES}

Bookstein, F.L. (1991). Morphometric tools for landmark data: geometry and biology. Cambridge University Press: Cambridge.

Bull, C.M., Griffen, C.L., Bonnett, M., Gardener, M.G. and Cooper, S.J.B. (2001). Discrimination between related an unrelated individuals in the Australian lizard Egernia strioltata. Behavioural Ecology and Sociobiology 50: 173-179.

Chapple, D.G. (2003). Ecology, life-history, and behavior in the evolution of complex sociality in lizards. Herpetological Monographs 17: 145-180.

Cogger, H. (2000). Reptiles and amphibians of Australia. Cornell University Press: New York.

Doughty, P., Kealley, L. and Donnellan, S.C. (2011). Revision of the Pygmy Spiny-tailed Skinks (Egernia depressa species-group) from Western Australia, with descriptions of three new species. Records of the Western Australia Museum 26(2): 115-137.

Duffield, G.A. and Bull, C.M. (2002). Stable social aggregations in an Australian lizard, Egernia stokesii. Naturwissenschaften 89: 424-427.

Gardner, M.G., Bull, C.M., Cooper, J.B. and Duffield, G.A. (2001). Genetic evidence for a family structure in stable social aggregations of the Australian lizard Egernia stokesii. Molecular Ecology 10: 175-183.

Gardner, M.G., Bull, C.M. and Cooper, S.J.B. (2002). High levels of genetic monogamy in the group-living Australian lizard Egernia stokesii. Molecular Ecology 11: 1787-1794.

Gardner, M.N., Hugall, A.F., Donnellan, S.C., Hutchinson, M.N. and Foster, R. (2008). Molecular systematics of social skinks: phylogeny and taxonomy of the Egernia group (Reptilia: Scincidae). Zoological Journal of the Linnean Society 54: 781-794.

Greer, A.E. (1970). A subfamilial classification of scincid lizards. Bulletin of the Museum of Comparative Zoology 139: $151-184$.

Greer, A.E. (1979). A phylogenetic subdivision of Australian skinks. Records of the Australian Museum 32: 339-371.

Greer, A.E. (1989). The biology and evolution of Australian lizards. Surrey Beatty and Sons Pty. Limited: Chipping Norton, Australia.

Horner, P. (1992). Skinks of the Northern Territory. Northern Territory Museum of Arts and Sciences: Darwin, Australia.

Horton, D. (1972). Evolution in the genus Egernia (Lacertilia: Scincidae). Journal of Herpetology 6: 101-109.

Hutchinson, M.N. (1993). Family Scincidae (pp. 261-279). In: Glasby, C.J., Ross, G.J.B. and Beesley, P.L. (eds.), Fauna of Australia. volume 2A: amphibia and reptilia. Australian Government Publishing Service: Canberra. 
Ingram, G. and Covaecevich, J. (1989). Revision of the genus Carlia (Reptilia, Scincidae) in Australia with comments on Carlia bicarinata of New Guinea. Memoirs of the Queensland Museum 27: 443-490.

Lappin, A.K. and Husak, J.F. (2005). Weapon performance, not size, determines mating success and potential reproductive output in the collared lizard (Crotaphytus collaris). American Naturalist 166: 426-436.

Lappin, A.K., Hamilton, P.S. and Sullivan, B.K. (2006). Bite-force performance and head shape in a sexually dimorphic crevice-dwelling lizard, the common chuckwalla [Sauromalus ater (=obesus)]. Biological Journal of the Linnaen Society 88: 215-222.

Lockwood, C., Lynch, J. and Kimbel, W. (2002). Quantifying temporal bone morphology of great apes and humans: an approach using geometric morphometrics. Journal of Anatomy 201: 447-464.

O'Connor, D.E. and Shine, R. (2003). Lizards in 'nuclear families': a novel reptilian social system in Egernia saxatilis (Scincidae). Molecular Ecology 12: 743-752.

O'Connor, D.E and Shine, R. (2004). Parental care protects against infanticide in the lizard Egernia saxatilis (Scincidae). Animal Behaviour 68: 1361-1369.

Pianka, E.R. (1986). Ecology and natural history of desert lizards. Princeton University Press: Princeton.

Pianka, E.R. and Vitt, L.J. (2003). Lizards: windows of the evolution of diversity. University of California Press: Berkeley, California.

Revell, L.J., Johnson, M.A., Schulte, J.A., III, Kolbe, J.J. and Losos, J.B. (2007). A phylogenetic test for adaptive convergence in rock-dwelling lizards. Evolution 61: 28982912.

Rieppel, O., Gauthier, J. and Maisano, J. (2008). Comparative morphology of the dermal palate in squamate reptiles, with comments on phylogenetic implications. Zoological Journal of the Linnean Society 152: 131-152.

Rolf, F.J. (2006). tpsDig, digitize landmarks and outlines, version 2.05. Department of Ecology and Evolution, State University of New York at Stony Brook. http://life.bio. sunysb.edu/morph/morphmet.html
Sheets, H.D. (2003). IMP software, integrated morphometrics software package, version 6a. Department of Physics, Canisius College, Buffalo, NY and Department of Geology, SUNY at Buffalo, NY. http://www.canisius.edu/ sheets/ morphsoft.html

Storr, G.M. (1968). Revision of the Egernia whitei species group (Lacertilia, Scincidae). Journal of the Royal Society of Western Australia 51: 51-62.

Storr, G.M. (1978). The genus Egernia (Lacertilia: Scincidae) in Western Australia. Records of the Western Australia Museum 6: 147-187.

Stow, A.J., Sunnucks, D., Briscoe, D.A. and Gardner, M.G. (2001). The impact of habitat fragmentation on dispersal of Cunningham's skink (Egernia cunninghami): evidence from allelic and genotypic analyses of microsatellites. Molecular Ecology 10: 867-878.

Stow, A.J. and Sunnucks, P. (2004). High mate and site fidelity in Cunningham's skinks (Egernia cunninghami) in natural and fragmented habitat. Molecular Ecology 13: 419-430.

Vitt, L.J. and Cooper, W.E., Jr. (1985). The evolution of sexual dimorphism in the skink Eumeces laticeps: an example of sexual selection. Canadian Journal of Zoology 63: 995-1002.

While, G.M., Uller, T., and Wapstra, E. (2009). Family conflict and the evolution of sociality in reptiles. Behavioral Ecology 20: 245-250.

Wilson, S. and Swan, G. (2003). A complete guide to reptiles of Australia. Reed New Holland: Sydney.

Zelditch, M.L., Sheets, H.D. and Fink, W.L. (2003). The ontogenetic dynamics of shape disparity. Paleobiology 29: 139-156.

Zelditch, M.L., Swiderski, D.L., Sheets, H.D. and Fink, W.L. (2004). Geometric morphometrics for biologists: a primer. Elsevier Academic Press: Amsterdam.

MANUSCRIPT RECEIVED 13 JANUARY 2010; ACCEPTED 6 MAY 2011 